\title{
EXPLORACIONES EN ÑAWINPUKIO, AYACUCHO
}

\author{
J. E. Gonzálwez Carré
}

\section{INTRODUCCIÓN}

El Instituto de Antropología de la Universidad de San Cristóbal de Huamanga desarrolló, entre los años 1963 y 1966, un Programa de Investigaciones Arqueológicas que tenía como finalidad el estudio de las sociedades prehispánicas desarrolladas en el actual departamento de Ayacucho, cuya área geográfica coincide con el área de influencia de dicha Universidad.

Las investigaciones arqueológicas centraban su atención y preocupación en el esclarecimiento de "los modos de comportamiento social, con énfasis en el estudio de la definición de los rasgos culturales, la organización social, y los procesos de cambio" de los pueblos que vivieron y habitaron dentro de la zona de influencia en los tiempos prehispánicos.

La organización y dirección del referido Programa de Investigaciones Arqueológicas estuvo a cargo del Dr. Luis G. Lumbreras, profesor de la Universidad de Huamanga en aquellos años.

\section{El SITIO De ÑawinPUKIO}

El sitio arqueológico de Nawinpukio se encuentra al Sur de la Ciudad de Ayacucho, aproximadamente a unos $6 \mathrm{~km}$ de distancia y se puede llegar a él siguiendo la carretera que conduce a las ciudades de Andahuaylas, Abancay y Cuzco. Nawinpukio se encuentra al lado derecho de la mencionada carretera y los terrenos que ocupa forman parte de un fundo agrícola conocido con el mismo nombre.

Por ser utilizado actualmente para fines agrícolas el terreno se encuentra removido y presenta un fuerte declive que sumado a la intensa precipitación pluvial ha producido un proceso de erosión y arrastre permanente de los materiales culturales hacia las partes bajas y concavidades propias de la topografía irregular de la zona. Por estas razones hay una fuerte mezcla de los materiales culturales y una total dispersión de los mismos en toda el área del yacimiento.

Este problema de la intensa acción erosiva que viene soportando Ayacucho, que tiende a ser más agudo por la ausencia de vegetación adecuada y técnicas orientadas a un aprovechamiento racional del agua de lluvia para evitar la acción destructora que ejerce sobre el terreno; de lugar a que la superficie de los yacimientos arqueológicos, que se encuentra en pendiente, sea permanentemente lavada produciendo el arrastre de los materiales hacia las partes bajas. 
En vista de que contábamos con un tiempo limitado para la realización de los trabajos, orientamos nuestros esfuerzos a la realización de una exploración y una recolección superficial de materiales, no pudiendo realizar excavaciones en lugares que sí presentaban indicios de mejores condiciones y posibilidades de obtener una información estratigráfica y cultural más amplia.

Se observa en Nawinpukio la existencia de muros totalmente derruidos y deteriorados en su mayoría, ya que las piedras han sido utilizadas para la construcción de viviendas y corrales por los campesinos que habitan actualmente el lugar.

Los muros que pudimos ubicar están construidos utilizando piedras de origen volcánico, de aspecto opaco, con porosidades y de color gris oscuro; se encuentran unidos con argamasa de barro formando un aparejo irregular no concertado, no existiendo evidencias de revoque en el paramento.

La total destrucción que presentan las construcciones imposibilita por el momento formarse una idea precisa de las características habitacionales de Nawinpukio, pero es posible pensar que se trataba de un poblado extenso por la cantidad de materiales y ruinas que se observan en la superficie del yacimiento y también por las estructuras que se encuentran formando recintos enterrados y cuya excavación es factible en el futuro.

La recolección superficial de cerámica fragmentada alcanzó la cantidad de 4110 tiestos y también algunos fragmentos de artefactos de piedra a los cuales se les viene denominando hachas.

Las primeras referencias sobre Nawinpukio las podemos encontrar en los estudios que realizaron toda una generación de pioneros de la Arqueología Regional de Ayacucho. El interés arqueológico de esta generación se tradujo en visitas, exploraciones y excavaciones en muchos yacimientos importantes, su interés estuvo centrado básicamente en los aspectos monumentales y las interesantes muestras del refinado arte de los antiguos pueblos prehispánicos de Huamanga.
En artículos, monografías y conferencias publicadas a nivel regional, podemos encontrar importantes referencias sobre los testimonios culturales que estudiamos, incluyendo noticias sobre hechos y elementos que en la actualidad ya no es posible observar porque no se encuentran in situ o porque curiosamente han desaparecido.

El conjunto de informaciones que comentamos constituyen invalorables fuentes de consulta para el investigador moderno aunque, en la mayoría de los casos, no tengan la rigurosidad científica deseable; pero sirven como puntos de partida para encontrar derroteros.

Pio Max Medina en su artículo "La Petrografía de Nahuiinpukio" (1935) nos da la descripción de unas petrografías encontradas por el señor Benedicto Flores en el lugar, y que consisten en la representación de serpientes bicéfalas sobre piedras. Establece una asociación de las petrografías con otros elementos del lugar y concluye afirmando que fueron los Pocras los antiguos habitantes de Nawinpukio.

El Sr. Lucio Alvizuri (1935), opina sobre las petrografías descritas por Medina, abundando en nuevas informaciones, que no es el caso reseñar aquí.

Un estudioso (1936), que prefiere permanecer en el anonimato, publica Petrografías de Nawinpukio describiendo la piedra en que se encuentran los grabados, detallando sus dimensiones y características, acompañados de un dibujo con la representación de dos serpientes bicéfalas.

Benedicto Flores escribió en 1944 un informe sobre Investigaciones Arqueológicas y al referirse a las petrografías descubiertas originalmente por él, considera que se trata de jeroglíficos prehispánicos descifrables.

Alfredo Parra Carreño comenta en La Historia Primitiva de Huamanga (1947) la importancia de la cerámica prehispánica y da los nombres de algunos yacimientos que se caracterizan por la cantidad y calidad de restos de alfarería. Menciona a Nawinpukio entre los lugares de mayor valor. 
Manuel Bustamante en "Basurales de Cerámica” (1950), informa sobre algunos depósitos de basura y alfarería prehispánica cuyo estudio y análisis es de gran utilidad para la comprensión de las culturas regionales.

Paralelamente a la tarea desarrollada por los estudiosos ayacuchanos se interesaron por la arqueología de la región, científicos como Alfred Kroeber y Julio C. Tello, habiendo dejado este último referencias generales. Alfred Kroeber en Peruvian Archaeology (1942), sostiene que los fragmentos Wari de la colección de Lila O’Neale, tienen relación estilística con Nasca y que Wari representa un deterioro de las manifestaciones nascoides, De acuerdo a lo que se viene suponiendo lo nascoide ingresaría en Ayacucho con Huarpa y estaría representado por la cerámica policroma que también hemos ubicado en Nawinpukio.

El análisis de la cerámica de Nawinpukio nos da nuevas evidencias para un conocimiento más profundo de las culturas regionales post-formativas en la sierra Central y estilísticamente, Ñawinpukio está comprendido dentro de los que se viene denominando Cultura Huarpa que vendría a ser la expresión regional más característica de Ayacucho. Pero el problema es mucho más complejo y lo que viene denominándose Cultura Huarpa, no constituye sino un material cerámico cuyo conocimiento está siendo ampliado con nuevas investigaciones orientadas a otros campos, lo que permitirá caracterizar culturalmente a Huarpa.

El estilo cerámico conocido como Huarpa fue reconocido originalmente por los arqueólogos Rowe, Collier y Willey quienes realizaron en 1946 una exploración especialmente en Wari. La publicación (1950), donde nos informaron los resultados de sus exploraciones contiene apreciaciones de lo observado en Wari y una clasificación preliminar del material cerámico que colectaron.

Bennett ubica cronológicamente a Huarpa como una manifestación tardía, que se desarrolla en el periodo Intermedio Tardío. Esta asignación de Bennett parte de los problemas estratigráficos que le presentaron sus excavaciones hechas sobre el terreno que había sufrido remoción y mezcla del material cultural. Ninguno de los pozos de Bennett tiene una estratigrafía homogénea y el contenido cultural lleva a la conclusión que presentan una fuerte mezcla de materiales en la mayoría de los casos. Huarpa se encontraba en las capas superficiales, pero también hay que tener en cuenta que materiales Huarpa se encuentran en casi todos los niveles y el pozo 4 de Bennett nos muestra un material Huarpa en una capa inferior que se encuentra diferenciada y separada de las capas superiores por una capa aluviónica; Bennett considera el pozo 4 como de estratigrafía invertida por comparación con sus otros pozos. Este problema de orden cronológico ha sido aclarado y discutido por Luis G. Lumbreras (1959) que con nuevos elementos de juicio ubica el complejo Huarpa como una cultura regional post-formativa.

Las investigaciones que posteriormente ha llevado a cabo el Instituto Antropológico de la Universidad de Huamanga han permitido tener valiosas evidencias estratigráficas, las que demuestran la posición cronológica temprana de Huarpa. Lamentablemente no es posible contar con las publicaciones de los últimos trabajos de Huamanga.

Duccio Bonavia, Luis Lumbreras y Félix Caycho (1958) durante la temporada de trabajo que llevaron a cabo en el sitio de Ayo Orjo, son los primeros en plantear y dar forma al problema cronológico de Huarpa al ubicar en Acuchimay y Ayo Orjo -lugares cercanos a la ciudad de Ayacucho- materiales Huarpa aislados de Wari en ciertos lugares y estratigráficamente también ubican a Huarpa como una cerámica post-formativa.

Si la ubicación cronológica de Huarpa viene siendo precisada con mayor claridad y certeza, los problemas tipológicos y estilísticos que presenta están todavía en una fase de discusión porque no se ha contado con suficiente cantidad de información para establecer una secuencia clara y estudiar el desarrollo completo y las relaciones del complejo Huarpa. Las hipótesis de trabajo planteadas hasta el momento, especialmente por Lumbreras (1959), han permitido avanzar en las investigaciones y replantear algunos problemas.

Wendell Bennett, en el trabajo que venimos comentando, no logra aclarar las diferentes manifestaciones estilísticas y tipológicas 
que encierra el complejo Huarpa; incluye dentro de una categoría no precisa a un conjunto de colecciones supuestamente relacionadas por rasgos repetidos pero no establece claramente si las diferencias y cambios en la decoración vendrían a implicar influencias foráneas y/o variaciones temporales entre varios tipos considerados estilísticamente como Huarpa o si se trata de variaciones locales o regionales.

Como hipótesis de trabajo se ha venido pensando que los grupos de manufactura como Nawinpukio Ordinario, Tosco o Alisado que describimos más adelante, representarían el nacimiento de Huarpa como expresión regional. El Huarpa Negro sobre Blanco, los kumunsenqa rojos y los tipos con decoración bícroma serían la manifestación cultural típica de la región y que luego por influencias nascoides sobre los pueblos de Ayacucho, Huarpa gradualmente cambia hacia una policromía donde ubicaríamos Huarpa Policromo y sus variedades.

Pero debemos afirmar claramente, que esta hipótesis de trabajo no ha sido confirmada hasta el momento y que las investigaciones que se vienen realizando sobre Huarpa pueden cambiar totalmente el esquema propuesto que se ha venido utilizando.

Analizando el material de Ñawinpukio pensamos que muchos tipos propuestos pueden dividirse en sub-tipos en el futuro y que los cambios observados de un tipo a otro pueden no representar diferencias en el tiempo sino desarrollos paralelos de diferentes modalidades dentro de una misma manifestación estilística. Por otro lado el paso de una bicromía a la utilización de mayor variedad de colores puede ser tomada como la aparición de una primera influencia nascoide de la costa pero contamos con algunas evidencias encontradas por el grupo de la Universidad de Huamanga en el sitio de Chupas en 1966, que demuestran que los contactos con la costa sur se empiezan a desarrollar desde el llamado Formativo, razón por la cual en el futuro podría demostrarse que la tradición policroma es contemporánea a la bicromía, que hoy se supone anterior.

Como podemos ver los elementos para solucionar el problema Huarpa son aún algo imprecisos, son muchas las interrogantes que se plantean y existen lagunas que deberán ser complementadas con trabajos de campo. La excavación de un poblado en forma extensa y el reconocimiento de la mayor cantidad de sitios con material Huarpa permitirán conocer en detalle las características culturales y establecer relaciones temporales y espaciales explicando los cambios internos de este periodo regional en el área de Ayacucho.

Llegar a explicarse el problema Huarpa es de excepcional importancia para comprender el origen y desarrollo del imperio Wari en la antigua sociedad andina a partir de Ayacucho. Es posible que poblados como Nawinpukio hayan servido como base para el surgimiento de la urbe de Wari y que luego coexistieron con la gran ciudad como agrupaciones dependientes.

Luis G. Lumbreras (1959) quien es el arqueólogo que más ha tratado los problemas de la Sierra Central y especialmente la región de Ayacucho, nos da una sugerente opinión: "... es importante tener en cuenta que hay la posibilidad de que en este periodo se inicie realmente la estructuración del centro de Wari, debido sobre todo a una posición hipotética que considera que los grandes centros urbanos, como parece fue el de Wari, se inician más antiguamente en Nasca, en toda la región de Ica, lo cual quiere decir que si Wari fue una urbe, cabe suponer que se comenzó a estructurar con la llegada de los elementos nascoides, puesto que Wari es posterior a Nasca en gran parte, aún si suponemos que Huarpa dio comienzo a la ocupación, como pudo ser en gran parte, aunque no con la morfología actual...", cabe anotar que aparte de Nawinpukio se han ubicado muchos lugares de población Huarpacomo Kurmunsenqa, Churukana, Anchakwasi y otros en la zona de Huanta que presentan indicios de haber sido lugares densamente poblados.

\section{La Cerámica}

La colección de cerámica superficial procedente de Nawinpukio, nos presenta, en sus aspectos tecnológicos y morfológicos, un conjunto de características relacionadas que permiten vertebrar la existencia de un grupo aislable culturalmente en el proceso histórico prehispánico de la región Ayacucho. 
Esta manifestación de la cultura material, representaría el desarrollo de una cultura regional post-formativa, a la cual se le viene denominando hasta el momento en forma general Huarpa, pero que encierra en su contenido un conjunto de problemas estilísticos y cronológicos que son de urgente solución para tener cabal comprensión del fenómeno regional andino para la Sierra Central del Perú.

La cerámica de Nawinpukio tiene un patrón bastante regular en su elaboración, es una cerámica modelada a mano, el tratamiento superficial predominante es un alisamiento, existiendo en algunos casos el pulido y el bruñido, interiormente también se aplica un brochado horizontal.

En la pasta predomina la oxidación y la utilización como antiplástico de cuarzo, mica, arena y material orgánico. La textura es bastante regular, denotando en la mayoría de los casos una conveniente selección de los materiales.

La decoración ha sido pintada antes de la cocción teniendo como colores básicos el negro, el blanco mate, rojo y gris. Los motivos decorativos son básicamente geométricos, y consisten en juegos de bandas y líneas horizontales y verticales que delimitan campos, adicionalmente se han utilizado manchas armoniosamente combinadas, cuadrículas y algunos motivos de filiación nascoide.

A continuación presentamos la descripción de la cerámica procedente de Nawinpukio, advirtiendo que el orden de presentación no tiene ninguna relación con el problema cronológico de la misma ya que la clasificación realizada no garantizaba una formulación cronológica que deberá ser precisada en el futuro. Por otra parte, nuestro estudio se circunscribe a un solo sitio y a una recolección superficial, lo que de hecho nos imposibilita dar respuesta rigurosa a muchas interrogantes.

\section{Huarpa Negro sobre Blanco}

La pasta en mayor proporción contiene arena, pero se nota también mica y cuarzo en peque- ñas cantidades, los elementos han sido bien mezclados y el color de la pasta varía de un naranja claro a oscuro, el cocimiento es de oxidación completa y la fractura regular.

La superficie ha recibido primero un baño de color blanco lechoso en su parte exterior y en algunos casos ante. Luego, sobre esta base, han sido pintados los motivos de color negro, interiormente también presenta el baño blanco lechoso y en algunos casos color ante oscuro, naranja claro o ausencia de baño.

Las superficies han sido tratadas con un aislamiento en ambos lados pero, en la superficie interior algunos tiestos han sido brochados horizontalmente.

Los bordes rectos, algunos ligeramente expandidos y los labios son planos, biselados o ligeramente redondeados con aberturas que varían entre $6,20,30,38$, 44 y $56 \mathrm{~cm}$. Las paredes presentan espesores de 4, 5, 8 y $10 \mathrm{~mm}$ a lo largo de los tiestos.

Los bordes han sido pintados de negro en ambas superficie, alcanzando a formar una banda de $3 \mathrm{~cm}$ a lo largo, que cubre ambos lados. Luego donde termina la pintura notamos rayas color ante claro que rodean la superficie. También existen líneas que forman cuadrados o rectángulos unos a continuación de otros en forma concéntrica. Las asas observadas son verticales.

\section{Huarpa Policromo}

El desgrasante está compuesto por pequeñas partículas de cuarzo arena y cerámica molida. La mezcla tiene una fina apariencia de color naranja claro a oscuro. La oxidación es completa y la fractura regular.

La superficie exterior tiene como base un baño color blanco lechoso y luego los motivos han sido pintados con colores negro y rojo que varían de claro a oscuro. En la parte interna presentan un baño color ante oscuro o claro y un color café; en algunos casos no hay baño sino un alisamiento pronunciado.

La superficie de los fragmentos ha sido tratada en ambos lados con un alisamiento, muy 
bien logrado, en la mayoría de los casos. Esporádicamente hay fragmentos que tienen un ligero pulimento.

Los bordes son rectos o ligeramente inclinados, de labios biselados en algunos casos. La abertura varía entre 14, 16, 24, $34 \mathrm{~cm}$. El espesor de las paredes varía entre 5, 7 y $14 \mathrm{~mm}$. Las bases son generalmente planas.

La decoración está compuesta por líneas negras de $3 \mathrm{~mm}$ de ancho y bandas rojas de 3 o $4 \mathrm{~cm}$. Las líneas negras y las bandas rojas circunscriben espacios de color blanco lechoso y también espacios color granate.

Otros motivos están formados por cuadrículas rojas y líneas negras verticales de $3 \mathrm{~cm}$ de ancho sobre fondo crema lechoso. Así mismo se encuentran triángulos rojos escalonados y pequeños puntos negros o rojos entremezclados. Un último motivo es la presencia de manchas negras o rojas de amorfa concepción.

\section{Huarpa Policromo sobre Ante}

La pasta contiene un desgrasante bien distribuido formado por cuarzo y mica principalmente, pero también pequeñas porosidades indican la utilización de material orgánico. El color varía de naranja claro a oscuro, la oxidación es incompleta en algunos casos y la fractura es regular.

La superficie ha sido alisada en ambos lados, pero solo algunos fragmentos presentan brochado interiormente. En la parte exterior la superficie ha recibido un baño de arcilla color ante y luego pintado los motivos de color negro, rojo y plomizo, interiormente carece de baño y es de color naranja claro.

Los bordes son rectos, ligeramente doblados, de labios aplanados o ligeramente redondeados, la abertura varía entre 14, 16, 20 y 26 $\mathrm{cm}$. La base es plana y el espesor de las paredes varía entre 7 y $8 \mathrm{~mm}$.

Encima de un baño color ante han sido pintadas líneas verticales color negro, plomo o rojo a lo largo de las piezas. En otros fragmentos han tomado una línea como eje al que han trazado un conjunto de líneas oblicuas. Las líneas tienen una dimensión de 4 y 6 mm.

\section{Huarpa Negro sobre Ante}

La textura de la pasta es completa, con un desgrasante de cuarzo y arena principalmente. El color de la pasta es de naranja claro a oscuro y la oxidación es incompleta. La fractura es regular.

El tratamiento superficial en ambas caras es de un alisamiento y un baño ante o gris en la cara interna.

Los bordes son rectos, expandidos o doblados de labios aplanados o ligeramente redondeados. Los bordes también presentan un ensanchamiento de apreciable grosor en algunos casos. La abertura varía entre 16, 18 y $44 \mathrm{~cm}$; la base es plana y el espesor de las paredes varía entre 6 y $8 \mathrm{~mm}$.

La decoración se compone de líneas negras de 2, 4 y $6 \mathrm{~mm}$ de ancho que corren verticalmente desde el borde a la base sobre un baño previo de color ante.

\section{Nawinpukio Negro sobre Naranja}

La pasta contiene un desgrasante compuesto de cuarzo y mica en finas partículas formando una mezcla homogénea. El color es de un naranja claro a oscuro, la oxidación es completa, pero hay un porcentaje que presenta oxidación incompleta. La fractura es regular.

La superficie ha sido tratada con un cuidadoso alisamiento en ambas caras y parece que algunos fragmentos tienen un ligero pulimento.

Los fragmentos tienen un baño en ambas superficies y luego han sido pintados los motivos. Exteriormente el color es naranja y los motivos en negro; interiormente el color es gris oscuro y naranja en algunos casos.

Los bordes son ligeramente abiertos, bastante engrosados y de labios aplanados o re- 
dondeados. La abertura es variable entre 40 y $48 \mathrm{~cm}$. La base es plana y el espesor de las paredes de 1 y $2 \mathrm{~cm}$.

El aspecto decorativo se compone de líneas negras de 3 y $4 \mathrm{~mm}$, pintadas encima del baño o base color naranja y corren verticalmente a lo largo de los fragmentos.

\section{ÑawinPukio Negro Decorado}

El desgrasante se compone de cuarzo y pequeñas cantidades de mica y piedra molida; la mezcla es irregular de poca compactación. La oxidación es incompleta y el color de la pasta es de un naranja oscuro en diversas tonalidades. La fractura es regular.

Exteriormente la superficie tiene un fino alisamiento y un baño color negro; interiormente tiene un baño y han sido brochados.

Los bordes son rectos, delgados, de labios aplanados o biselados, la base es plana y el espesor de las paredes varía entre 3 y $6 \mathrm{~mm}$.

La decoración se compone de líneas de color rojo oscuro de $3 \mathrm{~mm}$ de ancho pintadas sobre la base negra. En algunos fragmentos se notan ligeras manchas de flambé.

\section{ÑawinPukio Ordinario}

El desgrasante básico es el cuarzo que se presenta en forma abundante y uniforme en todos los fragmentos. La mezcla es irregular y de burda apariencia; el color es gris en la pasta y la fractura irregular. El cocimiento por atmósfera reductora.

La superficie presenta en ambas caras un alisamiento burdo que deja ver irregularidades por la presencia de granos del desgrasante. Exteriormente la superficie es negra, producto de la reducción, interiormente también es de color negro o ligeramente gris por la acción del fuego.

Los bordes son rectos, ligeramente engrosados y de labios redondeados o biselados, pre- sentando una abertura que varía entre 18, 20, 24 y $26 \mathrm{~cm}$. Las paredes tienen espesores entre 6 y $9 \mathrm{~mm}$; las bases son planas ligeramente combadas y también son mamiformes.

Los bordes en el labio tienen una banda pintada en forma irregular de color rojo oscuro y que por la reducción presenta manchas que no permiten distinguir este detalle decorativo con claridad.

La superficie externa de los fragmentos está cubierta por hollín de fogones y se puede notar claramente la acción del fuego sobre la arcilla que se encuentra frecuentemente quemada. Esto nos lleva a pensar que se trata de una alfarería de tipo utilitario doméstico.

\section{Ñawinpukio Tosco}

Se trata de un grupo de fragmentos que se caracteriza por una pasta burda con un desgrasante compuesto por cuarzo y arena en grandes partículas. El color de la pasta es café y gris parduzco. La fractura es regular y la oxidación incompleta.

La superficie no presenta baño en su parte externa y es de un color marrón diluido, interiormente es de un color parduzco y brochado horizontalmente.

Los bordes son ligeramente engrosados y los labios redondeados. La abertura de los bordes varía entre 26 y $28 \mathrm{~cm}$. El espesor de los fragmentos varía entre 8 y $7 \mathrm{~mm}$; notándose la presencia de bases mamiformes.

\section{Ñawinpukio Alisado}

La pasta se compone de un desgrasante a base de cuarzo y en menos proporción mica y material orgánico. El color de la pasta varía de naranja claro a oscuro. La fractura es regular y la oxidación completa.

Los bordes son de labios redondeados donde se nota huellas del modelado lo que da una apariencia de irregularidad. La abertura varía entre 14 y $20 \mathrm{~cm}$; el espesor de los fragmentos 
varía entre 6 y $9 \mathrm{~mm}$, la base es plana y ligeramente combada.

\section{ÑAwINPUKIO BRUÑIDO}

La pasta tiene un desgrasante a base de cuarzo en mayor proporción, pero también se notan partículas de mica. El color de la pasta es ante en varias tonalidades, la fractura es regular y la oxidación completa.

Exteriormente la superficie ha recibido un baño color ante oscuro con huellas de flambé por acción del fuego. El tratamiento final de la cara externa ha sido hecho con la aplicación de un bruñido muy bien logrado que deja huellas brillantes de su aplicación en forma horizontal y vertical.

La cara interna de los fragmentos es de un color gris y ha sido tratada con un alisado bien aplicado. Los bordes se caracterizan por tener labios planos, biselados y ligeramente redondeados, la abertura varía entre 16 y $26 \mathrm{~cm}$, el espesor de los fragmentos es de 7 y $8 \mathrm{~mm}$, siendo la base plana y las asas verticales.

\section{KumUNSENQA Rojo}

El color de la pasta varía de un naranja claro a oscuro presentando ligeras porosidades. El desgrasante se compone de cuarzo y arena. La oxidación es completa y la fractura irregular.

Exteriormente la superficie se encuentra alisada y se nota, además un ligero bruñido; está cubierto por una baño espeso color rojo que en algunos casos alcanza $2 \mathrm{~cm}$ al interior.

Interiormente es de un color plomizo y en algunos casos tiene un baño color ante, el único tratamiento es el alisado.

Los bordes son gruesos de labios redondeados y engrosados, también existen bordes ligeramente mas delgados, la obertura de los bordes varía entre 16 y $36 \mathrm{~cm}$. El espesor de los fragmentos es de 8 y $10 \mathrm{~mm}$.

\section{KumunSEnQA Marrón}

El desgrasante se compone de cuarzo, arena y material orgánico. La pasta es de color gris o naranja oscuro; la oxidación es completa y la fractura regular.

Exteriormente los fragmentos tienen un baño color marrón y un alisado. Interiormente no existe baño en algunos casos y en otros es de color ante, el tratamiento es de un alisado o un brochado.

Los bordes son ligeramente inclinados con un ligero reborde al exterior, de labios redondeados o aplanados. La abertura varía entre 18 y $22 \mathrm{~cm}$ y el espesor de los fragmentos entre 6 y $8 \mathrm{~mm}$. Las bases son planas y mamiformes.

\section{ÑawinPukio Pulido}

En el desgrasante se nota la presencia de cuarzo y mica formando una pasta bien lograda de color naranja claro. La oxidación es completa y la fractura regular.

La superficie exterior tiene un grueso baño color naranja y un acabado a base de un fino pulimento; interiormente, en algunos casos, los fragmentos presentan baños y pulimento y en otros hay ausencia de baño y sólo un alisamiento.

Los bordes son rectos, de labios aplanados o ligeramente engrosados al exterior. La abertura varía entre 24 y $42 \mathrm{~cm}$ y el espesor es de 10 y $18 \mathrm{~mm}$. La base es plana.

\section{Reconocimiento}

Nawinpukio fue uno de los lugares escogidos con la finalidad de realizar una exploración y recolección superficial del material. Los trabajos de campo los realizamos en octubre y noviembre de 1965 y el análisis de los materiales entre enero y abril de 1966; en junio del mismo año cumplimos con entregar un informe de trabajo al Consejo General de Investigaciones de la Universidad Nacional San Cristóbal de Huamanga, institución a la que expresamos nuestro reconocimiento. 


\section{BiBLIOGRAFÍA}

ALVIZURI, Lucio

1935 "Petrografía de Nahuinpukio, Ayacucho". Rev. Huamanga, Año I, № 5.

ANÓNIMO

1936 "Petrografías en Nawinpukio, Ayacucho". Rev, Huamanga, Año I, № 6.

BENNETT, Wendell

1953 "Excavations at Wari, Ayacucho, Perú". Yale University Publications in Anthropology № 49.

BUSTAMANTE, Manuel

1950 "Basurales de cerámica, Ayacucho". Anuario del Museo Histórico Regional, Año I № 1 .

GONZÁLES CARRÉ, J. E

1944 "Investigaciones arqueológicas, Ayacucho”. Rev. Huamanga, Año X № 56.

KROEBER, Alfred

1944 "Peruvian Archaeology in 1942". Viking Fund Publications in Anthropology № 4
LUMBRERAS, Luis; BONAVIA, D; CAYCHO, F

1958 Estudios arqueológicos en Aya-Orjo, Аyacucho. Lima, Universidad Nacional Mayor de San Marcos.

LUMBRERAS, Luis

1959 "Esquema arqueológico del a Sierra Central del Perú". Lima. Revista del Museo Nacional, Tomo XXVIII.

MEDINA, Pio Max

1934-35 "La Petrografía de Nawinpukio". Ayacucho, Rev. Huamanga, Año I № 1.

PEÑA CARREÑO, Alfredo

1947 "La historia primitiva de Huamanga". Ayacucho. Rev. Huamanga, Año XII. № 65.

ROWE, John; COLLIER, Donald; WILLEY, Gordon

1950 "Reconnaissance notes the site of Hauri, near Ayacucho". American Antiquity, Vol. XVI, № 2 . 
HUARPA - NEGRO SOBRE BLANCO
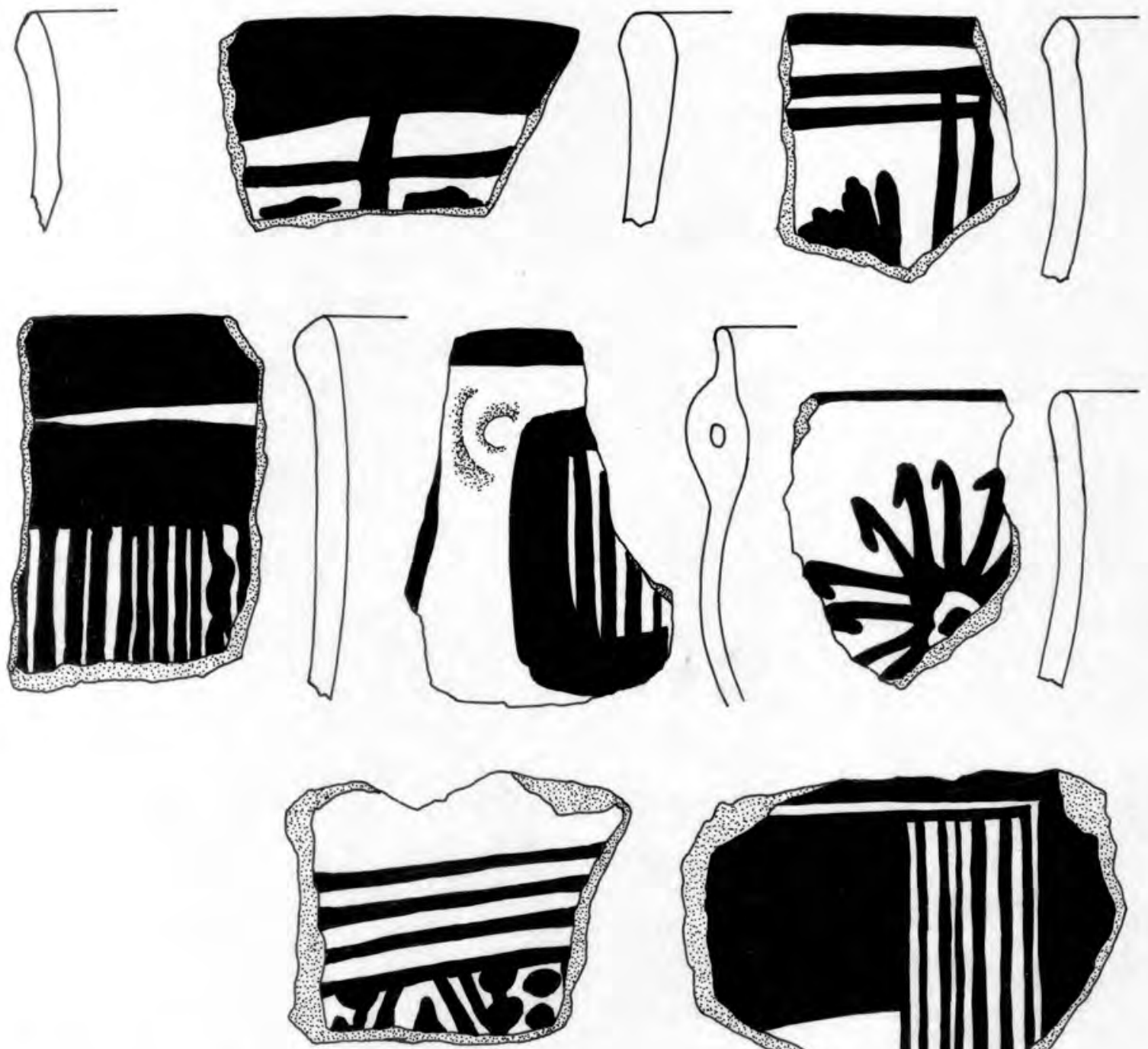

HUARPA - NEGRO SOBRE ANTE
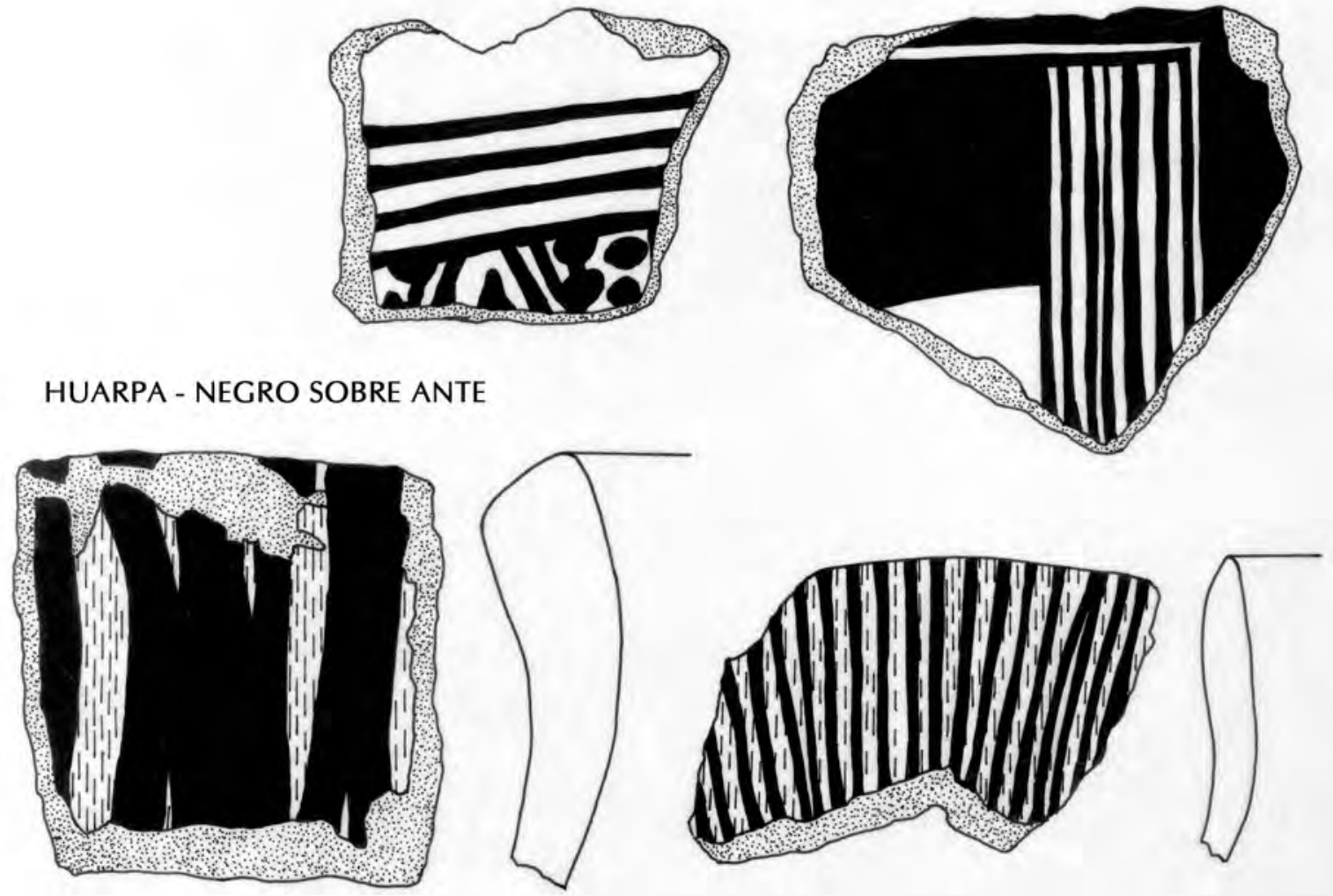
HUARPA - NEGRO SOBRE BLANCO
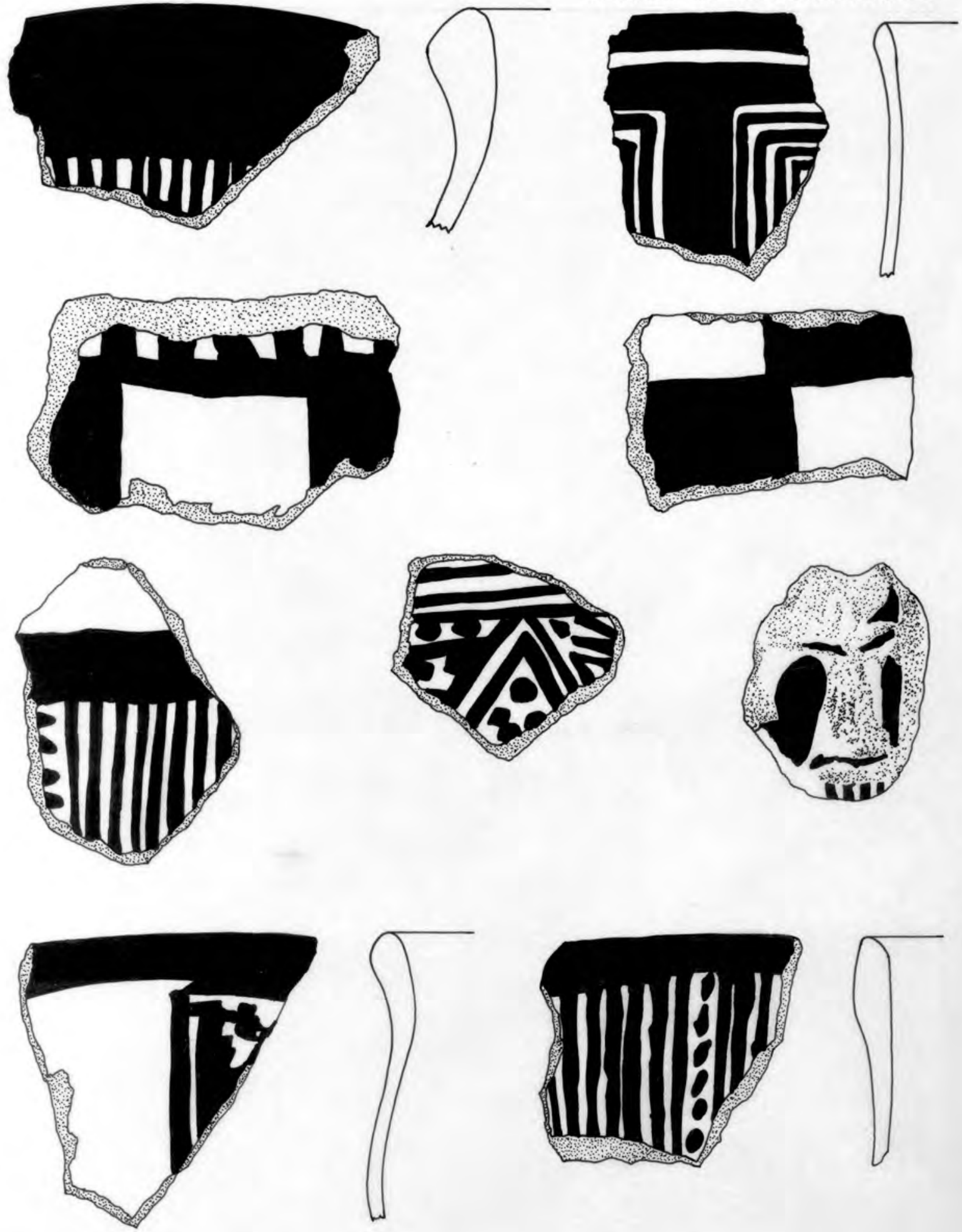
HUARPA - NEGRO SOBRE BLANCO
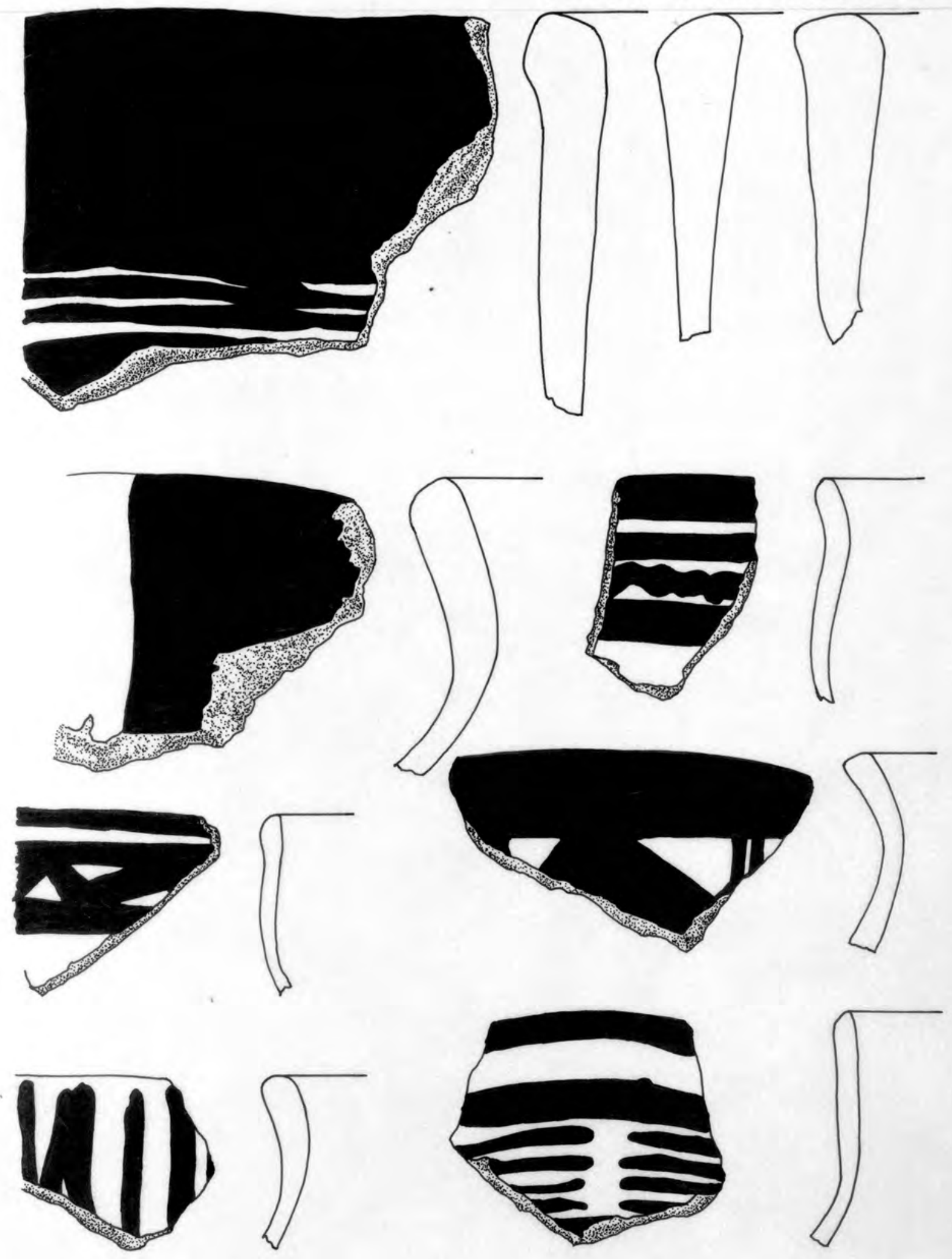
HUARPA POLICROMO SOBRE ANTE
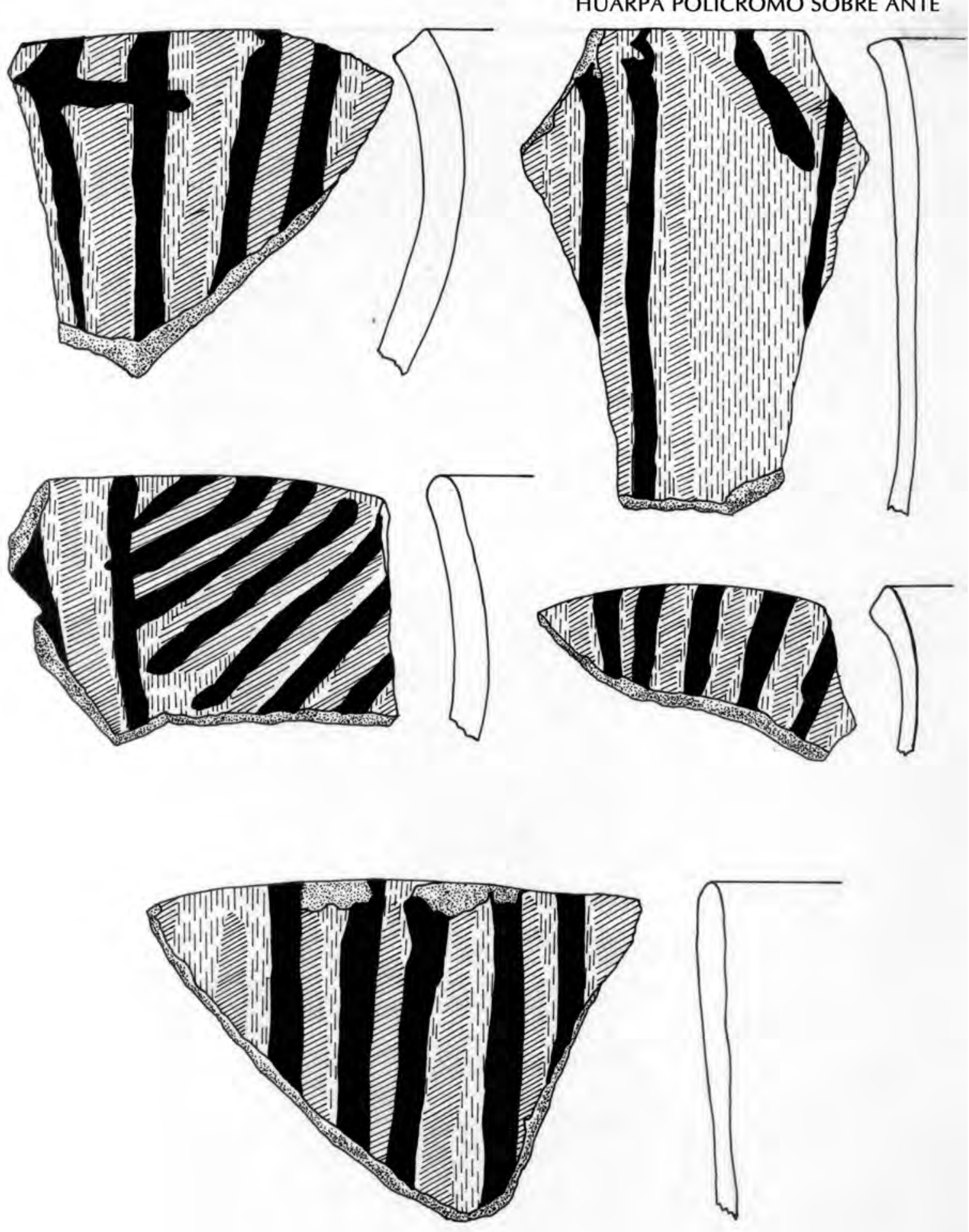
HUARPA - NEGRO SOBRE ANTE
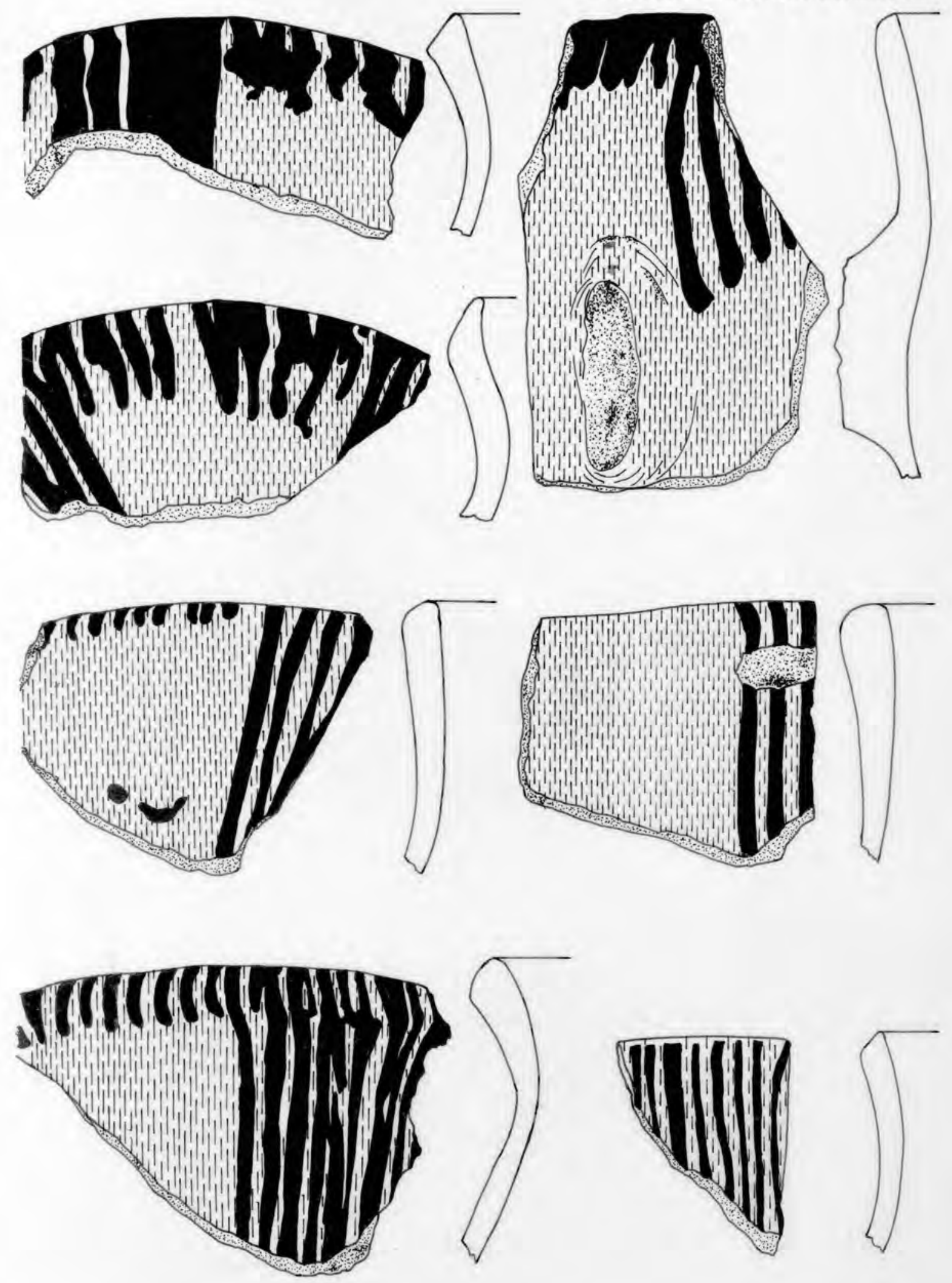
HUARPA - NEGRO SOBRE ANTE
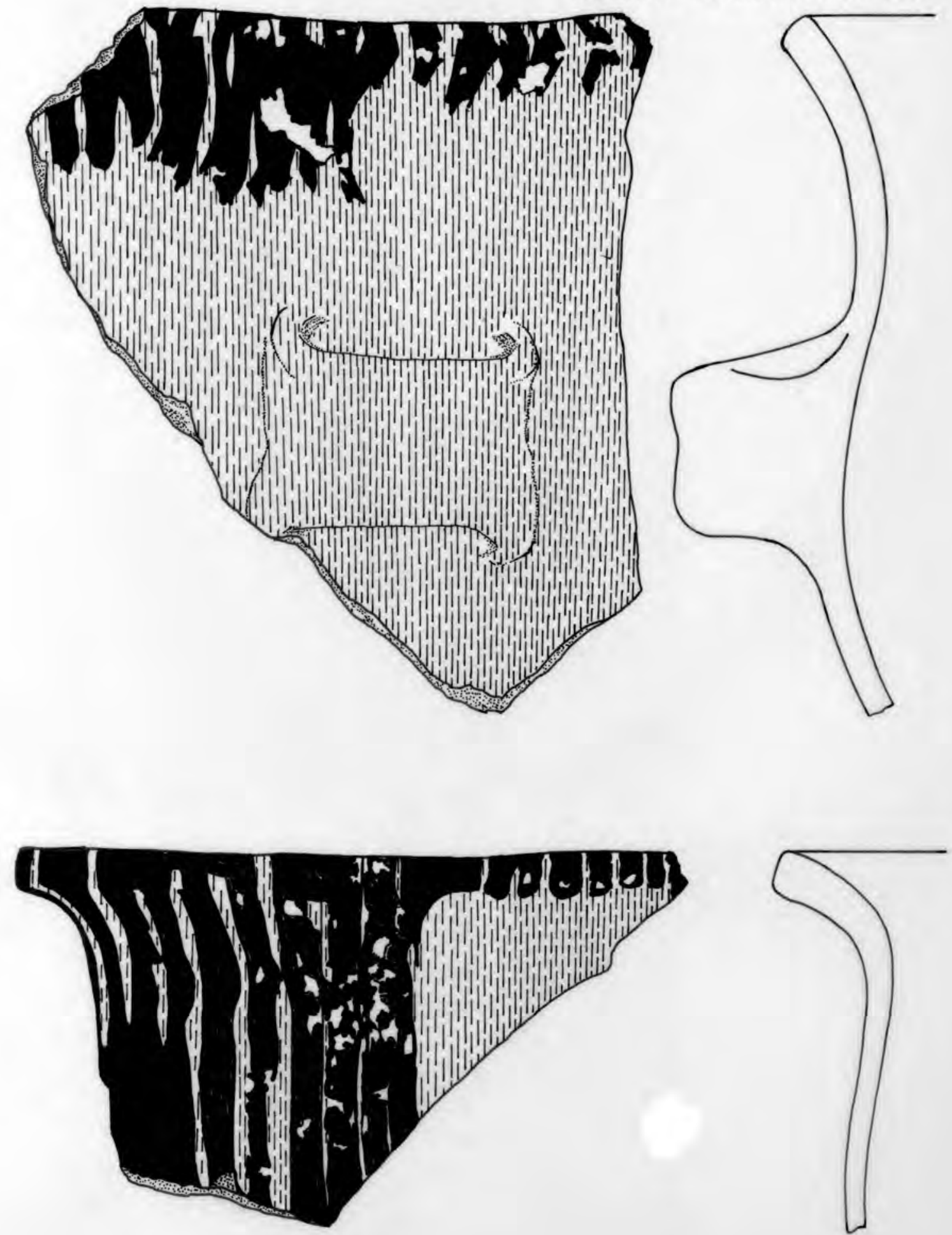


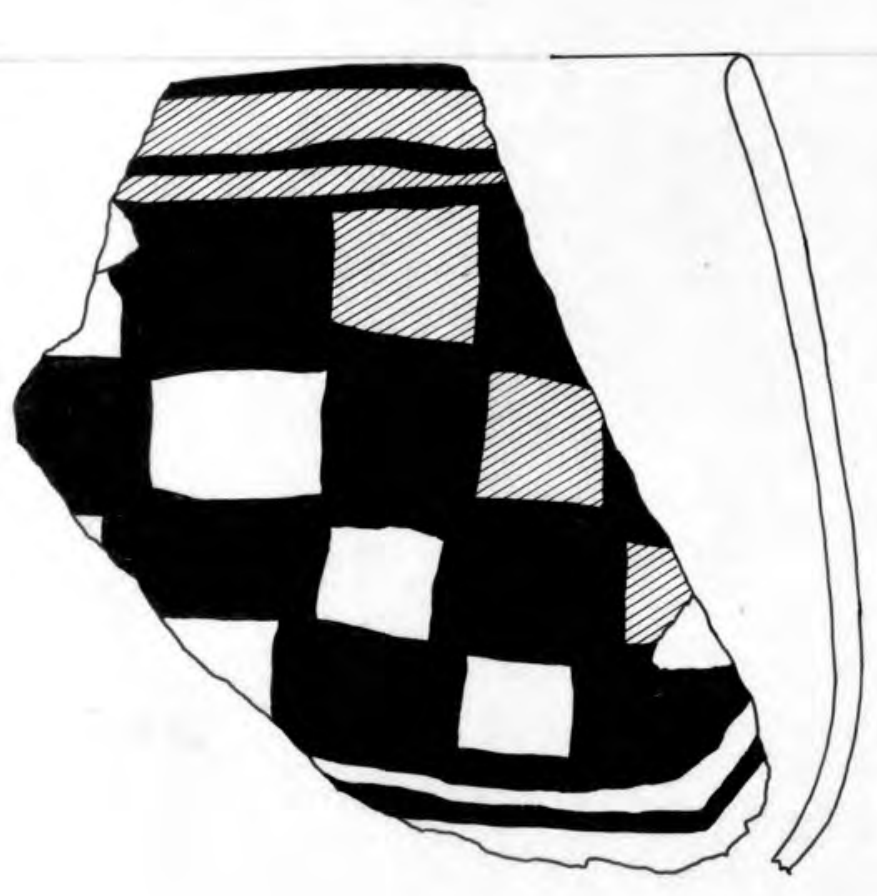

HUARPA POLICROMO

$$
\text { ESCALA }
$$
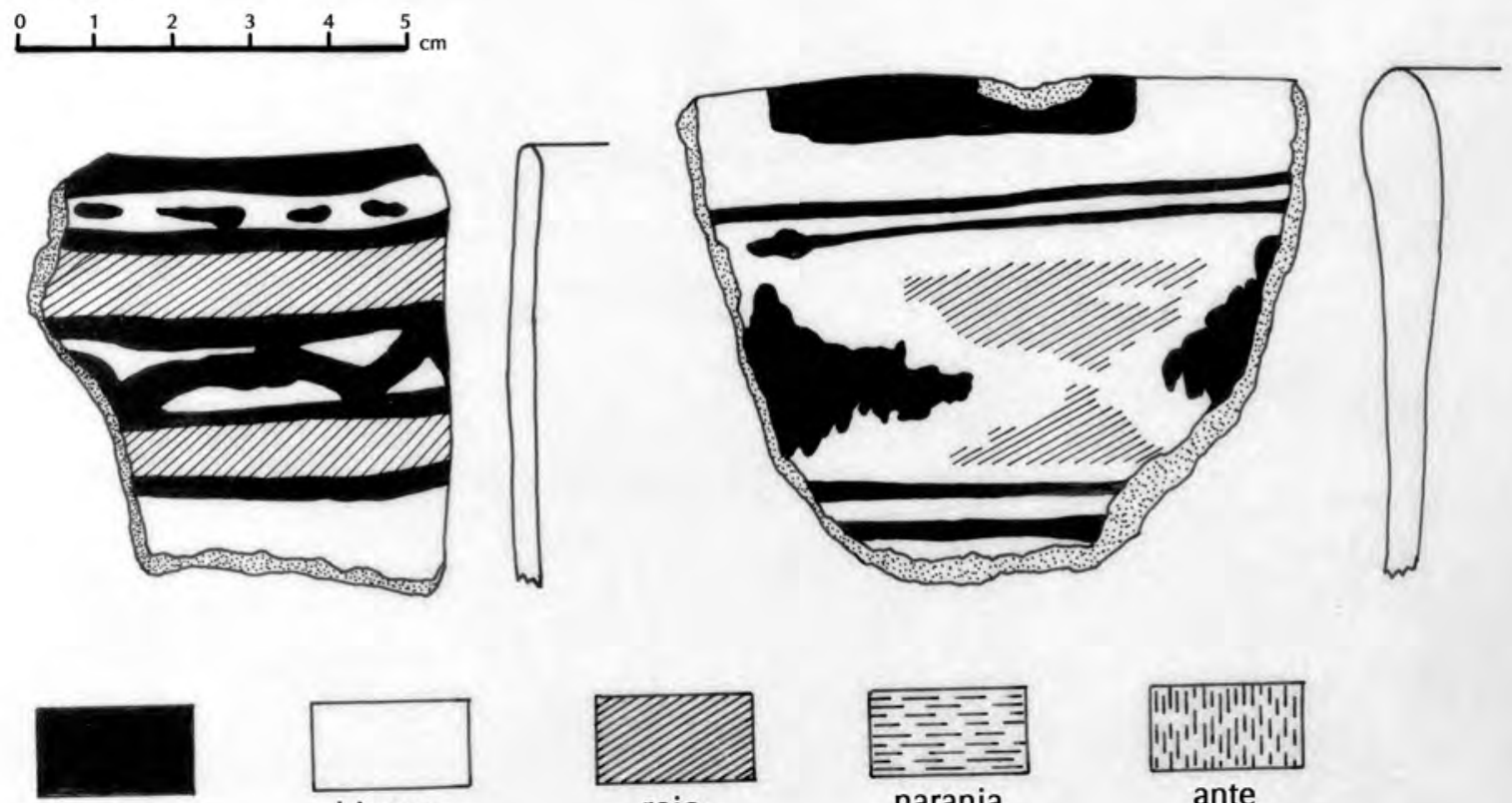

negro

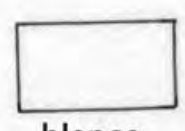

blanco

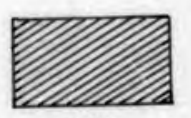

rojo

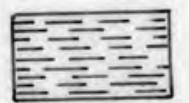

naranja
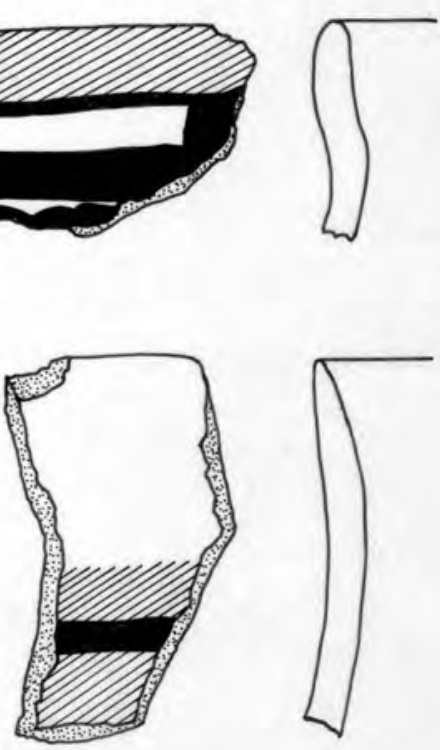
HUARPA POLICROMO
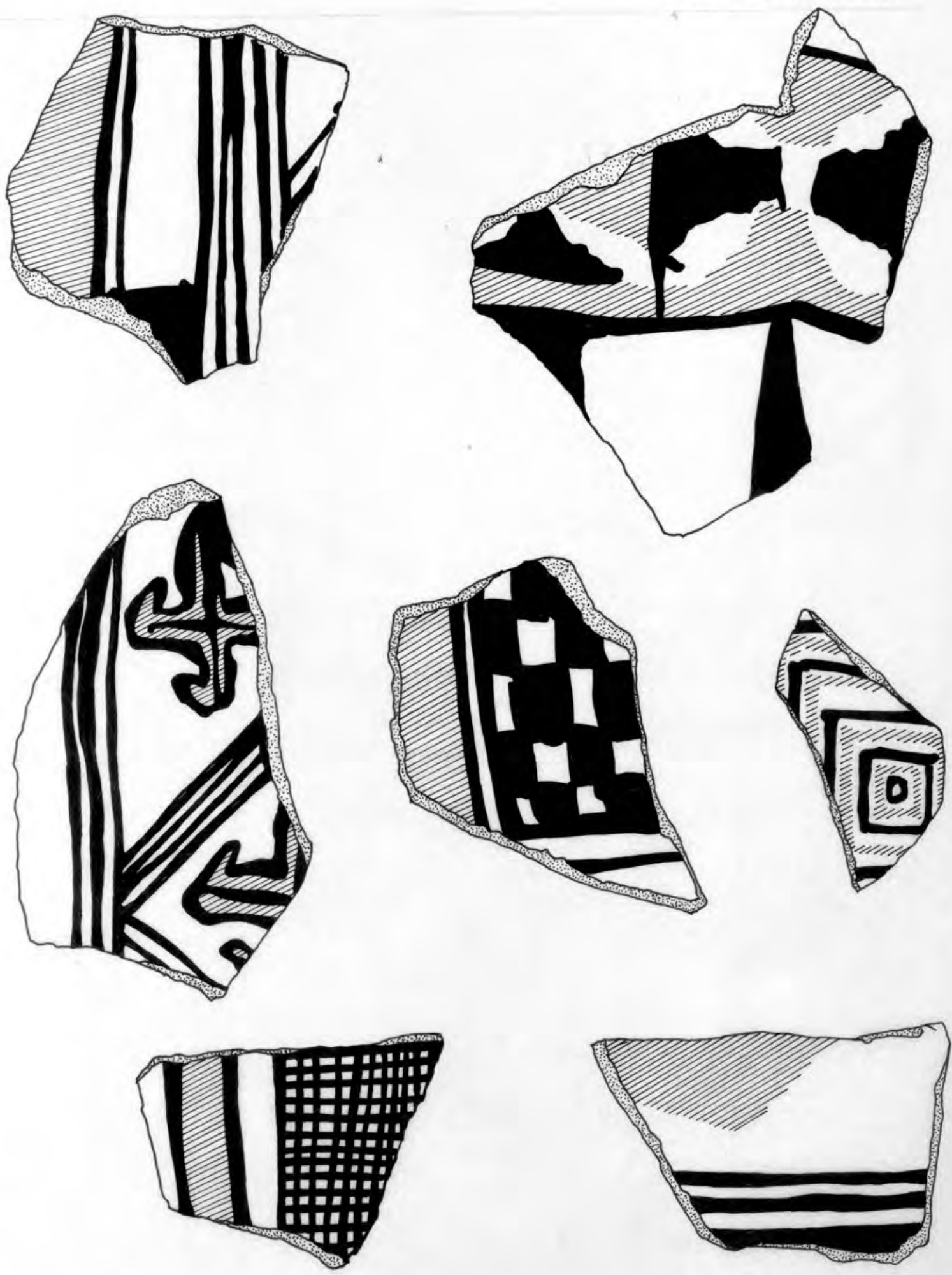
HUARPA POLICROMO
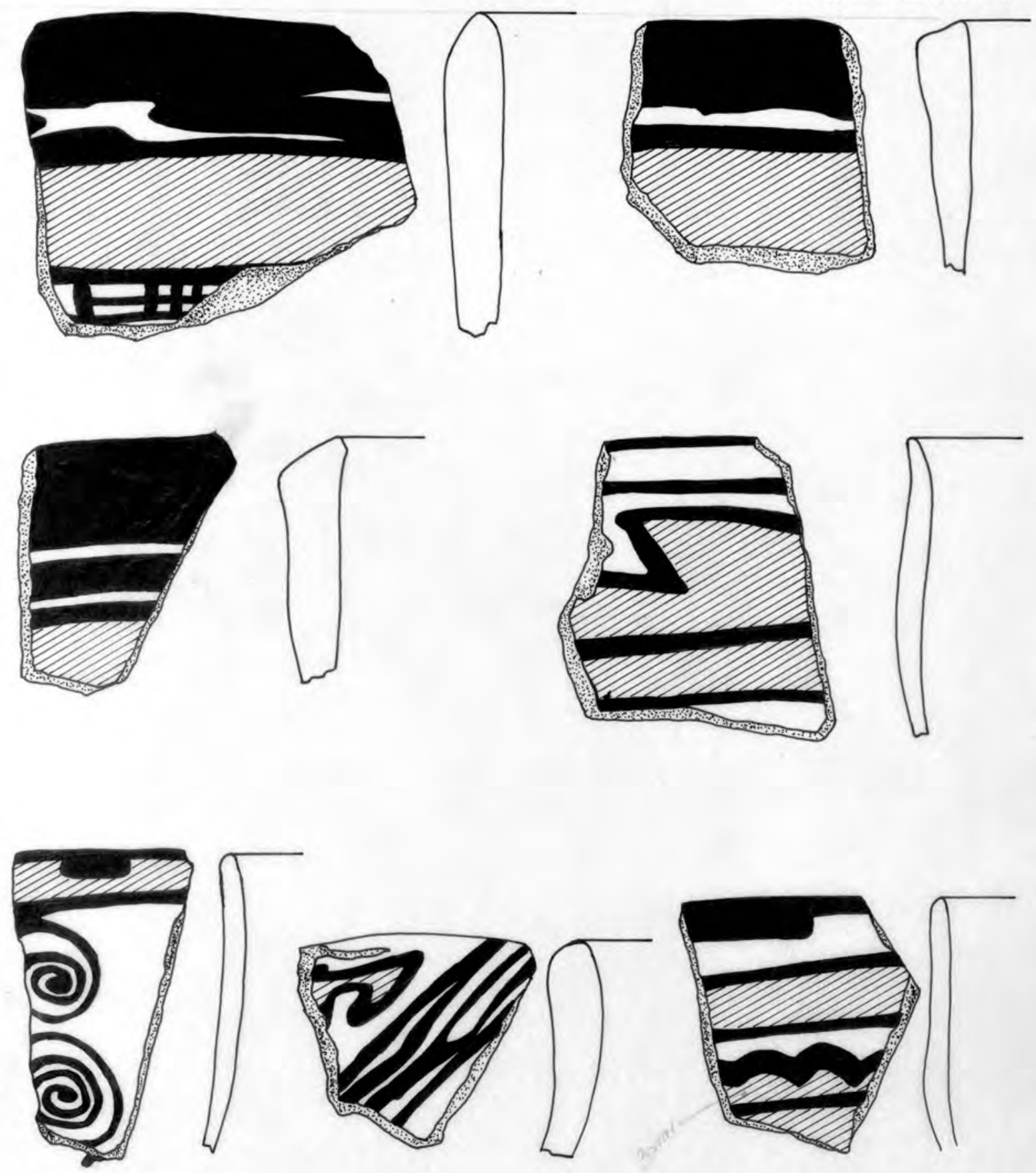
HUARPA POLICROMO
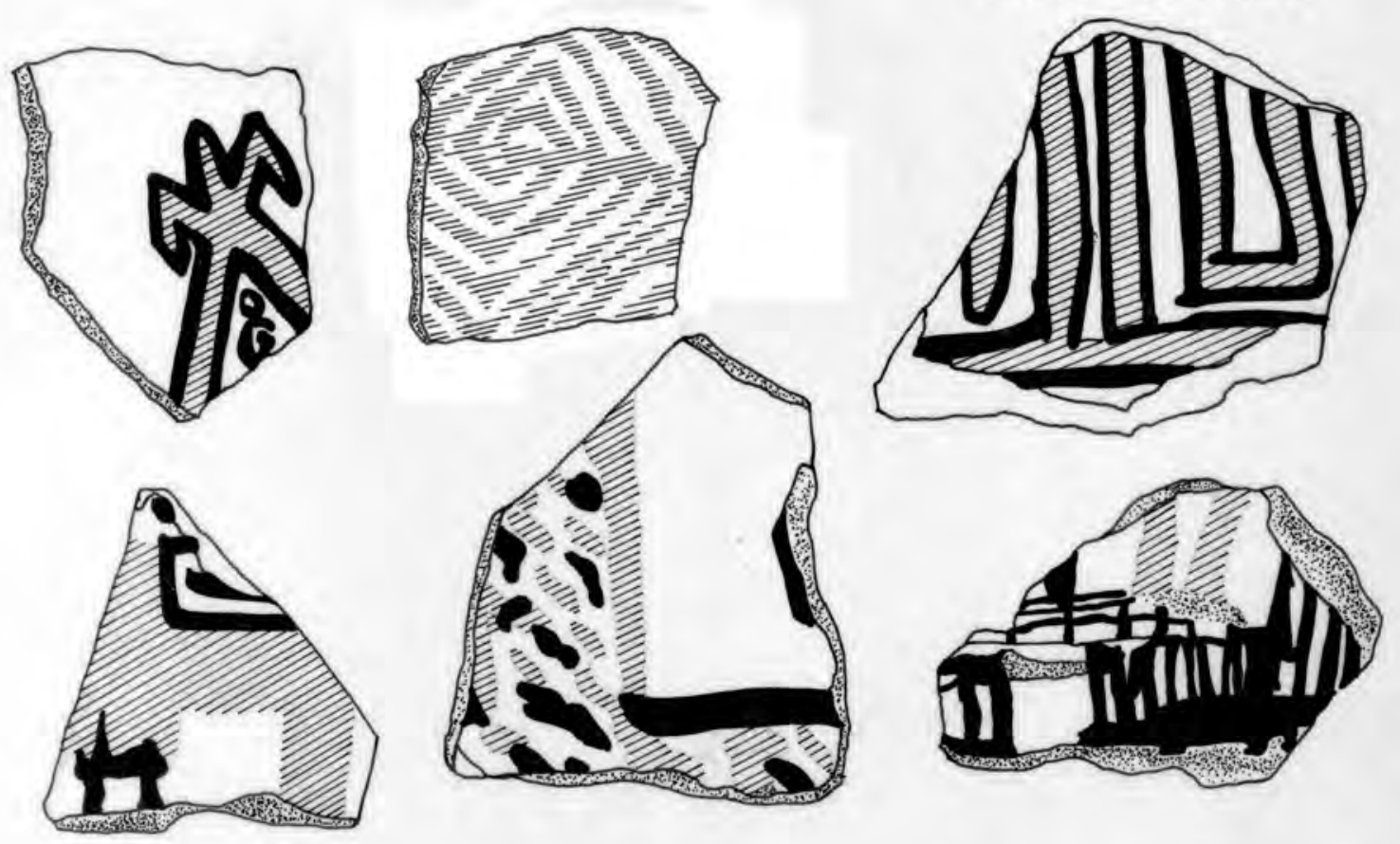

ÑAWINPUKIO NEGRO SOBRE NARANJA
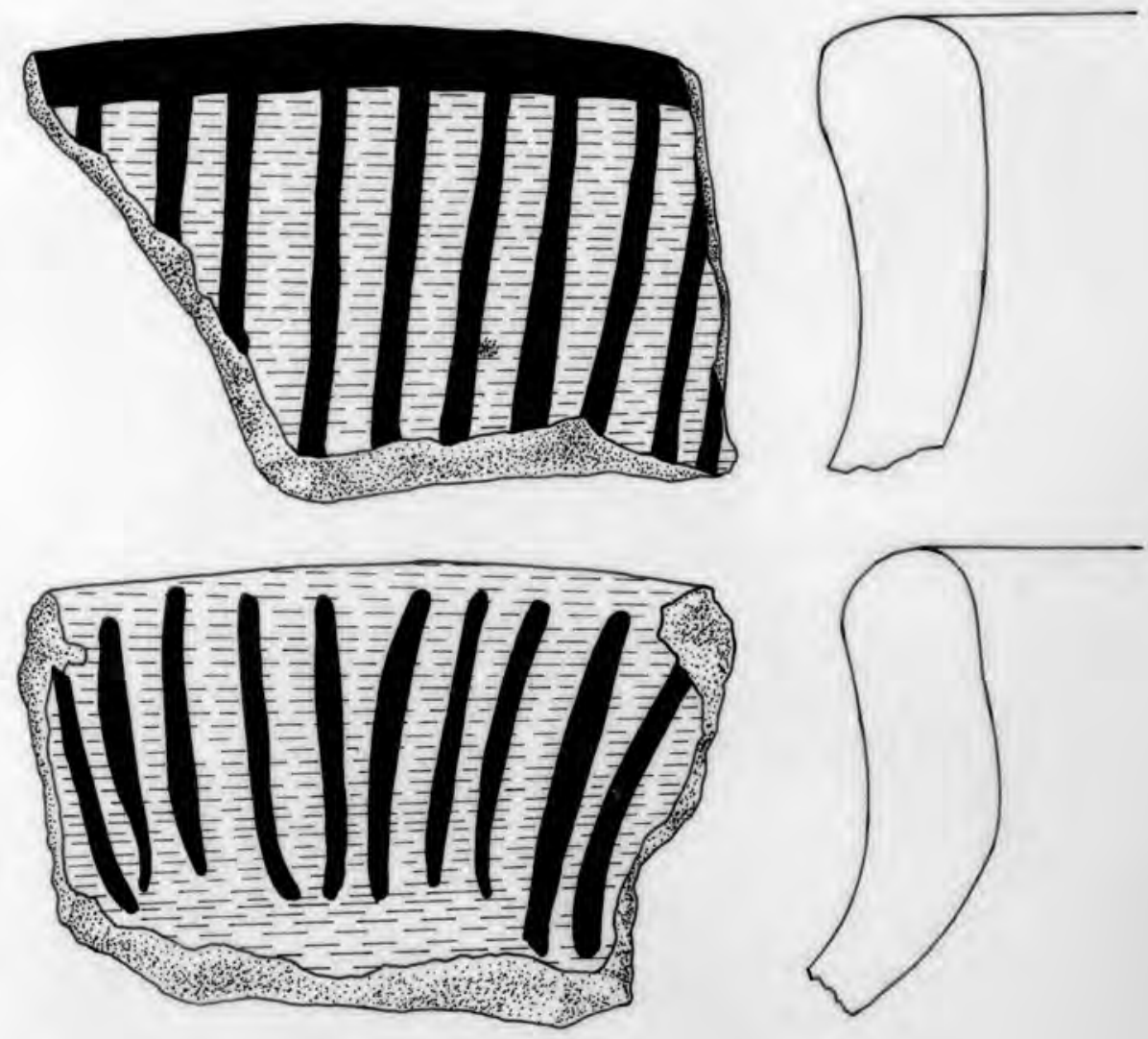


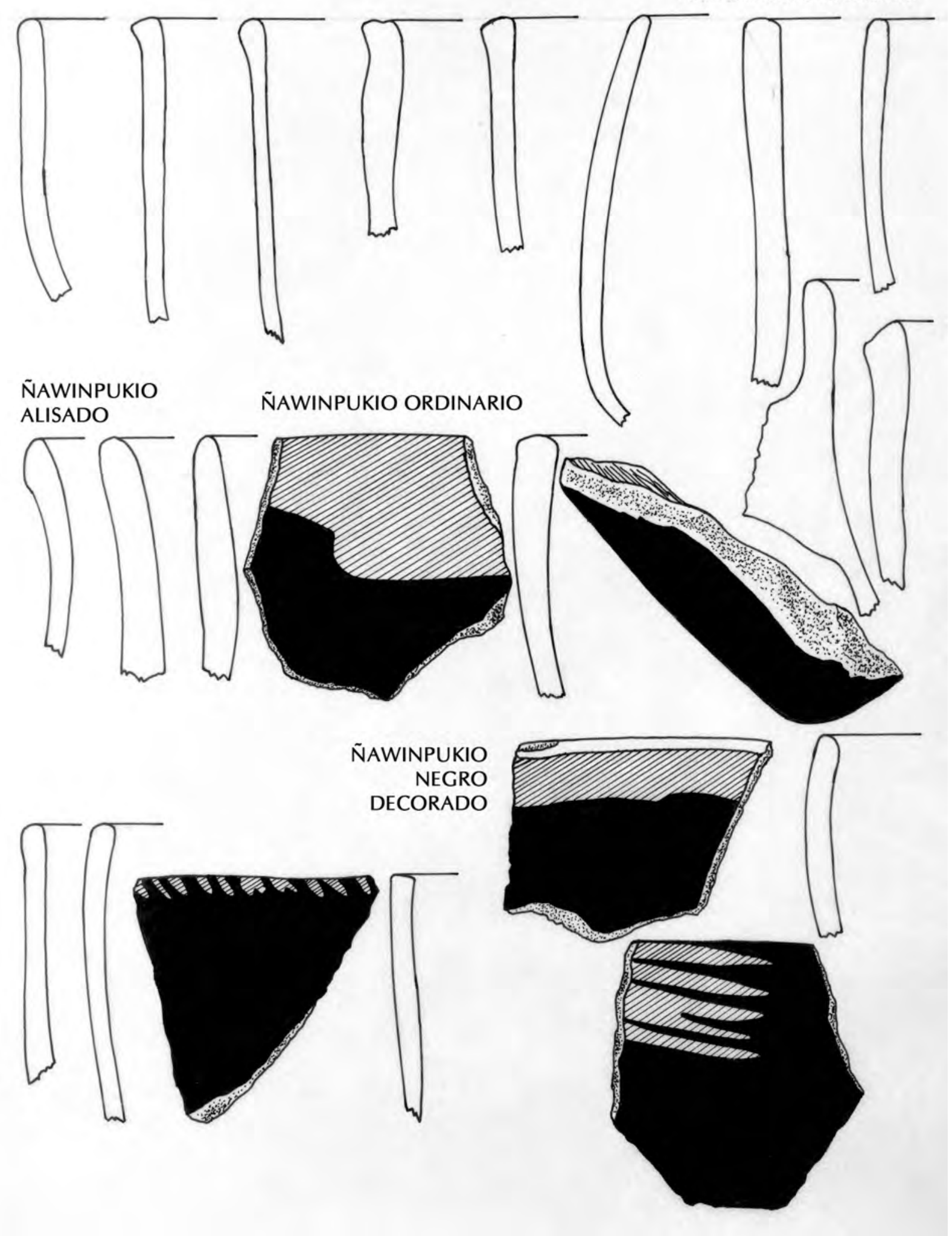



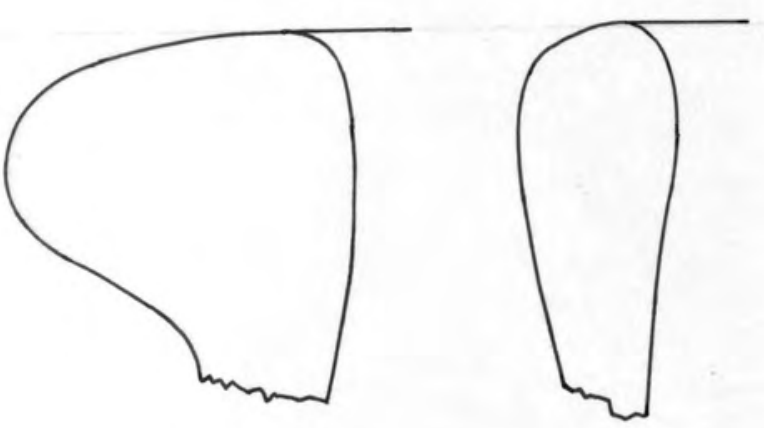

ÑAWINPUKIO PULIDO

KUMUNSENGA MARRON
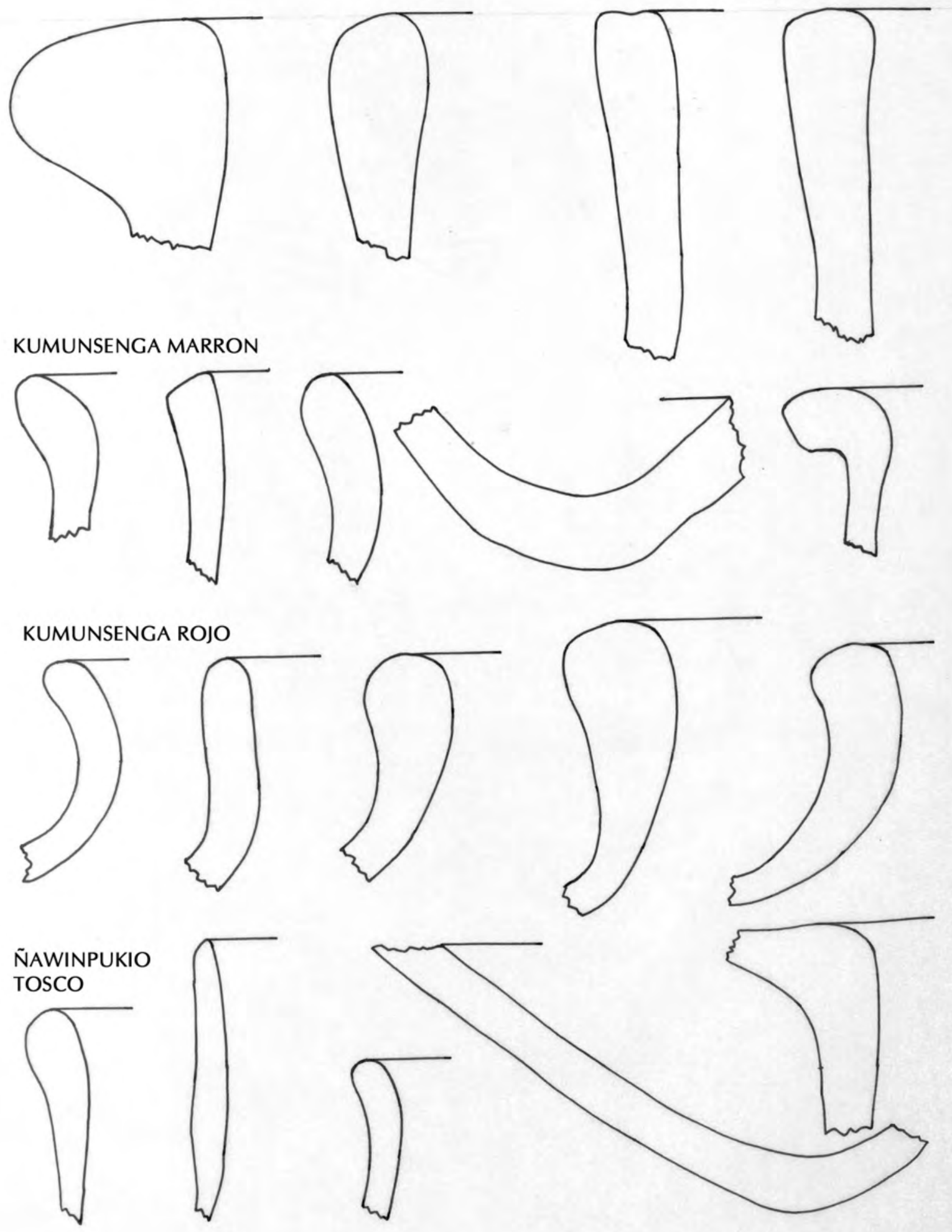